\title{
A Review of Risk Factors
}

\section{Assessed in Child Protective} Services

\author{
Thomas McDonald and Jill Marks \\ University of Kansas
}

Evaluating the likelihood of future maltreatment is a critical component of decision making in the child protective service process. A relatively recent phenomenon is the use of formal risk-assessment instruments for the collection of specific, generally quantifiable, data to help in this assessment. We compare the risk variables assessed in eight instruments currently employed and include results from a literature review to determine the empirical basis for use of the identified risk factors. The instruments differ in the variables included, and there is little empirical support for most of the included variables. However, subsets of variables can be identified that are common to most instruments and that have empirical support.

Assessing the risk of harm to a child is central to practice in the field of child welfare. Evaluating the likelihood of maltreatment is a key decision in the entire child protective service process. A relatively recent phenomenon is the use of formal data collection instruments to gather specific, generally quantifiable, data to assist in the assessment of a child's safety in the home and the likelihood of future maltreatment.

We review eight risk-assessment instruments currently in use throughout the country. The eight instruments included are the Alameda County California Reabuse Assessment Model, the Washington Risk Factor Matrix, the Illinois CANTS 17B, the Utah Risk Assessment Model, the Florida Health and Rehabilitation Services Child Risk Assessment Matrix, the Child Welfare League of America Child WellBeing Scales, the Child Welfare League Family Risk Scales, and the Action for Child Protection-Child at Risk Scales. An earlier document 
provides a comparative analysis of the eight risk-assessment instruments with respect to critical features and dimensions, including operational definitions, decisions in the child protective service process that are supported, timing of assessment, use of composite scores, integration with casework process, training requirements, reliability and validity tests, and length of time in use. ${ }^{1}$ Building on that comparative analysis, we examine the specific risk variables assessed by these eight instruments. The range of variables used to assess risk of harm is identified, the use of specific variables by the eight risk-assessment instruments is compared and contrasted, and the literature is reviewed to determine the empirical support for the predictive validity of each variable.

\section{Identification of Variables}

There were 88 variables identified in the eight risk-assessment instruments. These variables assess characteristics of the child; the primary caretaker; environment; maltreatment; the perpetrator's access to the child; the family; and parent-child interaction. The variables, grouped by categories, are presented in the first column of Appendix table Al. Column 2 of the table identifies the instruments that include each variable or some variation of the variable. (References cited in col. 3 are listed in App. B.) Researchers assigned variables to categories and identified the general categories. Possible conceptual ambiguities arising from such classification efforts are discussed in greater length later in this article.

Child characteristics. - Thirteen variables relate to characteristics of the child. These variables include descriptive attributes of the child, the condition and status of the child in several areas, the child's age, physical and mental health, behavior, educational status, and capacity for self-protection. Also included are the child's nutrition, clothing, personal hygiene, cooperation with the agency, and fear of the caretaker.

Caretaker characteristics. - The variables most frequently assessed are characteristics of the primary caretaker. Included in this domain are the capacity for and quality of physical and emotional care of the child. Characteristics of the caretaker such as his or her perceptions of stress, physical and mental health, and history of criminal behavior and substance abuse are also included, along with the caretaker's awareness of problems, motivation to solve them, and cooperation with the agency. Finally, the domain includes the caretaker's age and employment status. This domain contains 21 variables.

Environmental factors. - Sixteen of the variables concern the environment of the child and family. They include general living conditions of the family: household furnishings, sanitation, security and safety, level of overcrowding, and availability of utilities. Also included are environmental supports that are available and used by the family 


\section{Social Service Review}

such as formal and informal social support systems and accessibility of social services. Finally, general family characteristics are included, such as number of children in the home, family relationships, and stress on individual family members.

Characteristics of the maltreatment. - The fourth category of risk factors is the type, severity, and chronicity of the alleged or potential maltreatment. Seventeen of the 88 variables fall into this domain. Included is such abuse or neglect as deprivation of food and water, abusive physical discipline, physical confinement, deliberate locking out, sexual abuse, threat of abuse, and economic exploitation. The actual location of the injury is also documented. In addition, the severity and the frequency of abuse or neglect are assessed.

Perpetrator's access to child. - Three variables are included in this category. They are the access that the alleged perpetrator has to the child, the amount of time the alleged abuser spends with the child, and the protection offered the child through the presence of other people in the household.

Family characteristics. - Considerable ambiguity exists in the classification of these variables. Many of these variables could be listed under the domains of caretaker or environmental characteristics. For example, one instrument may view family relationships as a characteristic of the environment while another may view it as a family characteristic. Although similar data would be gathered in both instruments, differences are apparent at the conceptual level. Taking a more narrow view of the family domain, this review identified 10 family characteristics, including descriptive variables such as whether the biological father is in the household and variables concerning family functioning, family violence, victimization of other children, and the mental health status of other people in the household.

Parent-child interaction. - Some variables concern the interaction between parent and child or characteristics of the care given. Eight variables identified in this review include child's family relations, continuity of parenting, parental expectations, approval of child, consistency of discipline, stimulating the child, teaching life and parenting skills, and self-care of child.

\section{Analysis of Risk Factors}

All the instruments reviewed share a common philosophical base: rather than focusing on substantiating past abuse or neglect, they orient to the future. They also share the idea that risk should be assessed from a multidimensional perspective. With the exception of three instruments, information is gathered in all seven domains. Neither the Family Risk Scales nor the Action-Child at Risk instrument includes the perpetrator's access to the child. The Illinois instrument does not include any of the parent-child interaction variables. 
A summary of the risk variables used in the eight instruments is presented in Appendix C. Out of the 88 variables identified in the instruments reviewed, 15 were used by a majority of the instruments. The variables used most frequently by all of the instruments are parental capacity for child care and support for the principal caretaker.

These instruments suggest that making decisions regarding the risk of harm to a child involves assessing information gathered from a field of six domains. No consensus seems to exist concerning the importance of variables included under the seventh domain, family characteristics.

\section{Conceptual and Measurement Issues}

There is considerable diversity and ambiguity in the instruments in regard to how the variables are conceptualized and measured. In some instruments, data on a variable are directly assessed, while in others the same variable is assessed indirectly through inclusion in a broader category. For example, the variable "clothing" is measured in two instruments by assessing the amount and condition of the child's clothing. In the three other instruments that include this variable, child's clothing is measured as part of an examination of the physical needs of the child, the provisions made by the caretaker for the child's basic needs, and the severity and frequency of neglect.

For less objective variables, the approaches are even more disparate, and the complexity of the task more apparent. Because parental capacity for child care was a common variable (represented in all instruments), an exploration of the different ways it is conceptualized and measured across instruments is instructive.

Capacity for child care is conceptualized by two instruments (Washington and Illinois) as parenting skills and knowledge. The Family Risk Scales also define parental capacity in terms of the parent's knowledge of child care and development and competency in applying that knowledge. The Utah and Florida instruments appear to broaden the definition to include, in addition to skill and knowledge about child care, the parents' feelings, history of maltreatment as a child, view of the child, and beliefs and values about family, children, discipline, and child-rearing practices. The remaining three instruments each offer a different approach. The Alameda instrument focuses on the quality of physical care and quality of parent's affect toward the child. The Action-Child at Risk instrument defines capacity for child care as the parenting practices in the family. The last instrument, the Child Well-Being Scales, looks at capacity for child care in terms of the physical, mental, and behavioral characteristics of the parents.

The variation in the ways parental capacity for child care is defined, and subsequently measured across instruments, is representative of most of the variables with the exception of more objective variables 
such as age, number of children in the family, and services provided. In addition, the instruments offer diverse approaches to the actual assessment of risk. Some instruments (Washington, Illinois, Florida, Utah) assess risk on a scale from low to high, while others (such as Action-Child at Risk) rely on a descriptive account of parenting practices with an accompanying assessment of those practices as positive, negative, or traumatic. Some instruments combine separate variables under a broader concept as a single variable. For example, the Illinois instrument combines child's age and presence of mental or physical handicaps under a single variable, "child vulnerability." The Washington Risk Factor Matrix provides eight separate variables to measure severity of abuse or neglect, whereas most instruments measure severity with a single variable, if at all. The Action-Child at Risk instrument is unique in that descriptive information in narrative form is collected.

The same general pattern observed in regard to the conceptualization and measurement of individual variables also applies to the broader domains of parent, child, and environmental characteristics. While there is overall agreement that these domains should be addressed in determining the likelihood of harm to a child, there are more differences than similarities in the way these domains are conceptualized and measured. However, for the domains of severity and chronicity of abuse and neglect and the perpetrator's access to the child, there is considerably more agreement and a more narrowly focused and limited array of variables.

\section{Review of Empirical Literature}

A review of the literature on risk factors was conducted to determine the empirical support for the use of these variables as predictors of child abuse and neglect. The literature review was conducted through a computer search of research on risk factors for child abuse and neglect. Contacts with other risk-assessment researchers provided additional studies. We also used a previous review of the risk-assessment literature in child protection. ${ }^{2}$ Studies were categorized on the basis of the design and outcome measures used; they included prospective studies in which the outcome measure was recurrence of abuse or neglect based on reported or substantiated abuse or neglect, retrospective or prospective studies comparing abused or neglected children (any occurrence rather than recurrence) with a sample of cases that were not abused or neglected, and incidence studies describing characteristics of abuse or neglect cases or studies using a proxy measure of child abuse or neglect (e.g., parent stress).

Relevant studies are noted in the last column of the table Al for each of the 88 risk variables. Each reference is superscripted to denote the type of methodology described above. A complete reference list for these articles is provided in Appendix B. 
Of the 88 variables identified in the eight risk-assessment instruments reviewed, 39, or less than half, have been examined in the empirical literature. In the domain of child characteristics, six out of the 13 variables have been explored. Age and physical abilities of the child have received the most attention. In the domain of caretaker characteristics, which is the broadest domain in terms of the number of variables assessed, more than 60 percent (13 of 21) of the variables have been studied. Personal characteristics of the parent such as mental health and capacity for child care, demonstration of acceptance or affection for the child, and employment status have been assessed most frequently.

In the environmental domain, two variables have been tested more than any of the other identified variables. Support for the principal caretaker and the stress on parents have been consistently studied over the past 20 years. Of the maltreatment characteristics, history, severity, and frequency of the abuse or neglect have been studied most extensively with only limited research on the other variables. In the family characteristic domain, family violence and parental response to child behavior or misconduct have been assessed.

In this literature review, the prospective studies in which the outcome measure was recurrence of abuse or neglect (indicated by an asterisk in table A 1) provide the most rigorous, direct, and relevant test of the utility of variables for the assessment of risk in the context of child protective services. Because these studies center on predicting the recurrence of child abuse, they will be the primary focus of the following review. The findings of other research efforts will, however, also be noted.

Will Johnson and Jill l'Esperance focused on predicting the recurrence of physical abuse. ${ }^{3}$ Their randomly selected sample included two subgroups of cases that were referred for physical abuse. In the first group of 65 cases, there was no known recurrence of abuse while the case was open and no subsequent referral to the agency for abuse within 2 years of the initial referral if the case was closed. In the other subgroup of 55 cases, a subsequent incident had been reported within 2 years of the initial referral.

Information in these case records was used to obtain data on the potential predictors of recurrent abuse that were identified in a literature review. The data collection instrument included a large number of possible correlates of abuse ( 105 variables). Of the 105 variables tested, a discriminant function containing five variables was 74 percent accurate in distinguishing reabuse from nonreabuse cases. Variables intended to measure stress (more than one child in the home and a Likert-scale measurement of the amount of time the abuser spends with the child) were positively related to the repetition of abuse. That is, families with more than one child and those in which the abuser spends more time with the child had a higher incidence of recurrence than did families 
with one child and more limited contact time between the child and abuser. Variables that appeared to measure parent coping skills (the reasonableness of the mother's expectations of the child and a Likertscale rating of the mother's parenting skill) were negatively related to reabuse. Better coping skills, therefore, were associated with lower incidence of reabuse. In addition, a variable intended to measure the client's capacity to use resources (Likert-scale rating) was also negatively related to the repetition of abuse. Thus, a greater capacity to use resources was associated with lower incidence of reabuse.

In another study, Christopher Baird conducted research to develop a risk-assessment index for the Alaska Department of Health and Social Services. ${ }^{4}$ Data on more than 100 variables were collected on each of 550 randomly selected families referred to the Family Services Section of the department during 1985. Information gathered covered the period from the date of the referral through the next 12 months.

The results of the analysis indicated that, while there is some overlap in predictive variables of continued abuse and neglect, the best results were attained when abuse and neglect were analyzed independently. Some factors related to abuse, for example, were not related to neglect. This study, therefore, resulted in two scales. One scale contained 12 variables found to be predictive of continued abuse, and the other scale contained nine variables predictive of subsequent neglect. Based on discriminant function analysis, the strongest predictors of abuse were prior reports of abuse, prior placements, number of children in the home, and negative social relationships. These variables were positively related to the recurrence of physical abuse. The two strongest predictors of neglect were single-parent homes (recurrence more likely) and age of caretaker (the older the caretaker, the less likely a recurrence).

Continuing the research on predicting the risk of harm to a child, but not differentiating between abuse and neglect, J. Weedon, Thomas Torti, and Phillip Zunder evaluated the Family Risk Assessment Matrix developed by the Vermont Division of Social Services. ${ }^{5}$ To determine the reliability and validity of the instrument, 147 families were assessed. The total scale score, and three of the 14 variables in the matrix, were found to be predictive of a subsequent founded report of abuse or neglect. The three variables were (1) child's age and physical and mental abilities, (2) severity and frequency of neglect, and (3) perpetrator's access to child. Risk-level assignments based on scale cutoff scores also appeared to be effective in predicting subsequent abuse or neglect. Additional multivariate statistical analysis led the authors to conclude that risk prediction is not unidimensional. One dimension may be family functioning, while a second independent dimension may be the child's age and ability level. Though this study did not attempt to differentiate between subsequent abuse and neglect, the 
authors concluded that further investigations should attempt to distinguish risk factors associated with each.

There is agreement among the researchers in these three studies that abuse and neglect should be studied independently because different factors appear to be involved in each. There is also agreement among these three studies that significant predictors of reabuse or subsequent neglect involve information gathered from several domains, thus supporting the idea that child maltreatment is the result of many factors occurring simultaneously.

Appendix D presents significant predictors of recurrence of child maltreatment found in these three studies. Although the results suggest a range of risk factors, there appears to be agreement about two variables - the perpetrator's access to the child and the number of children in the home. The results suggest that the more access the perpetrator has to the child, the more likely the child will be abused or neglected again, and if there is more than one child in the home, reabuse or neglect is more likely to occur.

In addition to the above-cited studies, which focus on predicting the recurrence of abuse or neglect from reported or substantiated cases, many research efforts have focused on predicting the initial instance of abuse or neglect. These studies, in which abuse or neglect is an outcome measure, and in which some control or comparison group is employed, are indicated in table Al with daggers. Other relevant research (labeled with double daggers) includes descriptive incidence studies of child abuse and neglect cases (with no comparison or control groups) and studies that use proxy measures such as parental stress rather than direct measures of abuse or neglect as the outcome variable. The results of these studies suggest that child characteristics correlated with abuse or neglect may include age of the child, physical or behavior disabilities, or a perception of difference by the caretaker. The mental health status of the parent is also suggested as a risk factor, and there is a general finding that an interplay of mental, physical, and emotional stresses underlies abuse. A relationship between employment status and child maltreatment has also been found by numerous investigators from several different perspectives. Lack of support for the principal caretaker and stress on the parents have also been found to be related to abuse and neglect in these studies.

\section{Summary and Conclusion}

An analysis of the eight instruments reviewed in this study determined that 88 separate variables could be identified even when ignoring variations in how each variable was measured and whether it was separately recorded or part of some subscale. Given that no single instrument uses more than 44 separate variables and that most use 
considerably fewer (as few as 13), there is a clear lack of agreement in the field about what one should consider when assessing risk. This is not surprising, given ambiguities about the concept of risk; the reliance of most instruments on practice wisdom in their development suggests considerable variation in the practice field or the need to use more reliable and valid methodologies for capturing practice wisdom. It is possible that workers may follow different paths to the same conclusion. That is, different workers may look at different aspects in conducting an assessment but still arrive at similar overall assessments. The critical issue for future research on the use of risk assessment in child protective services is whether individual variables, combinations or interactions of variables, or workers' judgments are predictive of future harm to the child.

Less than half of the variables measured in these instruments have been empirically tested, much less validated, by even the weakest of research designs. Only a handful of studies have directly tested the predictive validity of variables assessed at the initial report or investigation for their ability to predict recurrence of maltreatment. The lack of a solid body of empirical research, of course, has contributed to the variation observed in the instruments reviewed. However, only two agencies (in Alaska and Alameda County, California) have taken the seemingly obvious strategy of first assessing the predictive validity of data gathered in the risk-assessment process and then using these results in the construction of a risk-assessment instrument. Most agencies have adopted one of the available risk-assessment instruments, frequently with some modification, or have developed their own hybrid version based on several sources and the experience of agency personnel. These largely untested instruments have then been put in place for use by child protective service staff. Some agencies then embark on or plan validation studies. Once in place, however, it becomes much more difficult to evaluate these tools, particularly with respect to measuring false positives (incorrectly labeled high risk) that may be confounded by intervention, such as removal of the child from the home. In this context, evaluations are much more likely to discover false negatives (incorrectly labeled low or no risk). Further development of such risk-assessment instruments is likely to lead to more intervention to remedy false negative assessments without identifying situations in which no or less intervention would have sufficed at reduced cost to the agency and with less disruption to the family involved.

The review described here raises many questions but also provides some insight and suggestions for future development. Current practice guidelines and research findings suggest the need for multidimensional perspectives in assessing risk. However, to date, both have focused much more attention on the caretaker and environment than on the child, family structure, characteristics of the maltreatment, and parent- 
child interaction. Research results presented here, which show significant predictors in several domains, suggest that a more balanced weighting in the construction of risk-assessment instruments is warranted.

Major work remains in defining and measuring both the dependent variable (risk) and the independent variables (factors to be assessed) that define the work of risk assessment. Risk is variously defined to include safety of the child at the time of the investigation, likelihood of any future maltreatment (regardless of severity), and need for outof-home placement, which can be, but is not necessarily, linked to the child's safety. Considerable ambiguity exists concerning the definition and measurement of risk factors describing the child, caretaker, family, and environment. This is less true with respect to characteristics of the maltreatment and perpetrator's access, which tend to be more reliable measures, which have been shown to be consistently important predictors, but which are frequently overlooked as measures. Ambiguities do arise with respect to characteristics of the maltreatment. Does one treat these measures as predictors or develop separate prediction models for different types of maltreatment? Results to date suggest the need for separate prediction models for physical abuse and neglect; however, it is not clear whether further distinctions are needed. The inability to develop prediction models with at least limited generalizability across populations and agency settings may ultimately defeat the purpose of these data collection instruments if findings seem to suggest that risk assessment is a highly idiosyncratic process. However, the findings from the three prediction studies reported here hold promise that prediction models for basic abuse and neglect categories (physical abuse, sexual abuse, and neglect) can perform reasonably well. The use of computers to construct risk scores can make the process manageable for the child protective service worker if the number of variables assessed can be limited. Again, limited experience suggests that a small subset of the information currently collected can be used to arrive at fairly accurate predictions. Collection of additional data must be justified on other grounds.

Finally, in the attempt to capture relevant dimensions of the caretaker, the child, the family, and their interaction, care should be taken not to overlook the more obvious, objective characteristics. Variables such as the number of children and adults in the home and age of caretaker have been found in some of the more rigorous research to be useful predictors of recurrence of maltreatment.

It should be remembered that risk-assessment systems serve several functions. The use of more formal procedures and systems, including the use of risk-assessment instruments, has contributed to the standardization of data collection in child protective services and can help guide the child protective service worker through the assessment and service planning process. Our focus has been on the use of risk-as- 
sessment instruments for predicting future recurrence of maltreatment. This focus is justified from the perspective that such prediction is central to the decision-making process in child protective services. On the basis of the review presented here, we conclude that the use of risk-assessment instruments has spread without adequate testing of the predictive validity of these instruments. However, the results of studies conducted by Johnson and l'Esperance in Oakland, Baird in Alaska, and Weedon, Torti, and Zunder in Vermont hold considerable promise and point the way for other agencies in the development and testing of risk-assessment instruments.

\section{Appendix A}

\section{Table A1}

Risk FACTORS IN RISK-AsSESSMENT INSTRUMENTS

\begin{tabular}{ccc}
\hline $\begin{array}{c}\text { Variable } \\
(1)\end{array}$ & Instrument & Reference \\
\hline & $(2)$ & $(3)$ \\
\hline
\end{tabular}

Child characteristics:

Age

Physical abilities/disabilities

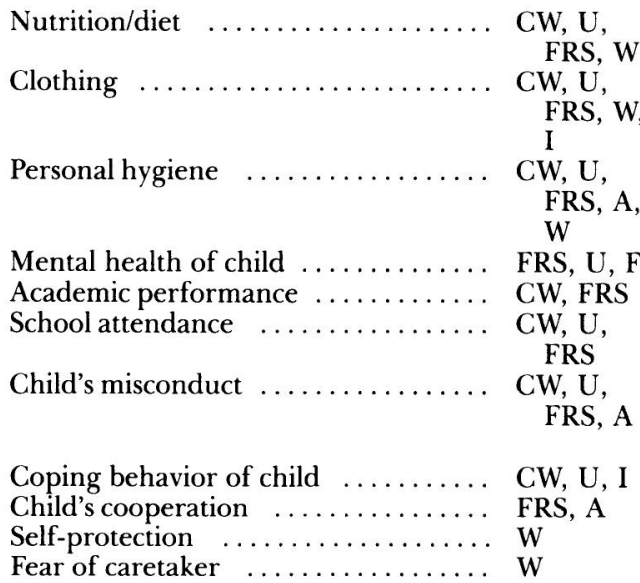

Caretaker characteristics:

Physical health care of child

CW, FRS,
W, I, F, U CW, U, F,
I, W
Milner and Ayoub 1980†; Rosenberg et al. 1982; Polansky et al. $1978 \dagger$

Hawkins and Duncan 1985†; Kadushin and Martin 1981‡; National Center on Child Abuse and Neglect 1982‡; Simons et al. 1966 ; Weedon et al. 1988*

Milner et al. 1984†; Milner and Wimberley 1979, 1980†; Schneider et al. 1980†; Webster-Stratton 1985†; Weedon et al. 1988* Milner and Ayoub $1980 \dagger$

Milner and Wimberley 1979, $1980 \dagger$; Webster-Stratton $1985^{\dagger}$

Egeland and Sroufe 1981†; George and Main 1979† 
Table A1 (Continued)

\begin{tabular}{|c|c|c|}
\hline $\begin{array}{l}\text { Variable } \\
\text { (1) }\end{array}$ & $\begin{array}{l}\text { Instrument } \\
\quad(2)\end{array}$ & $\begin{array}{l}\text { Reference } \\
\quad(3)\end{array}$ \\
\hline \multicolumn{3}{|l|}{ Caretaker characteristics (Continued): } \\
\hline Mental health care of child ...... & $\begin{array}{l}\text { CW, U, } \\
\text { FRS }\end{array}$ & \\
\hline Supervision of child & $\begin{array}{l}\text { CW, FRS, } \\
\text { W, U, A }\end{array}$ & \\
\hline Arrangement of substitute child care & CW, FRS & \\
\hline Money management $\ldots \ldots \ldots \ldots \ldots$ & $\begin{array}{l}\mathrm{CW}, \mathrm{FRS} \\
\mathrm{U}\end{array}$ & \\
\hline Parental capacity for child care ...... & $\begin{array}{l}\text { CW, FRS, } \\
\text { U, A, W, } \\
\text { I, ACT, } \\
\text { F }\end{array}$ & $\begin{array}{l}\text { Dumas and Wahler 1983†; } \\
\text { Johnson and l'Esperance } \\
1984^{*} \text {; Milner and Ayoub } \\
1980 \dagger \text {; Polansky et al. 1978†; } \\
\text { Susman et al. } 1985 \dagger\end{array}$ \\
\hline Parental relations & $\begin{array}{l}\text { CW, FRS, } \\
\text { ACT }\end{array}$ & \\
\hline Parental recognition of problems .... & $\mathrm{CW}, \mathrm{W}, \mathrm{U}$ & \\
\hline Parental motivation to solve problems & $\begin{array}{l}\text { CW, U, } \\
\text { FRS, I }\end{array}$ & Baird 1988* \\
\hline \multicolumn{3}{|l|}{ Parental cooperation with } \\
\hline case planning/services & $\begin{array}{r}\text { CW, W, I, } \\
\text { U, FRS, } \\
\text { ACT, A }\end{array}$ & $\begin{array}{l}\text { Baird 1988*; Egeland et al. } \\
\text { 1980†; Johnson and } \\
\text { l'Esperance } 1984\end{array}$ \\
\hline \multirow{2}{*}{$\begin{array}{l}\text { Parental acceptance of/affection for } \\
\text { child } \ldots \ldots \ldots \ldots \ldots \ldots \ldots \ldots \ldots\end{array}$} & & \\
\hline & $\mathrm{CW}, \mathrm{U}, \mathrm{W}$ & 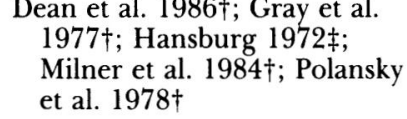 \\
\hline Parents' physical health $\ldots \ldots \ldots \ldots$ & $\begin{array}{l}\text { FRS, U, } \\
\text { ACT, w, } \\
\text { I, F }\end{array}$ & \\
\hline Parents' mental health $\ldots$ & $\begin{array}{l}\text { FRS, U, } \\
\text { ACT, A, } \\
\text { W, I, F }\end{array}$ & $\begin{array}{l}\text { Anderson et al. 1986†; Baird } \\
1988^{*} \text {; Milner and Ayoub } \\
198 \dagger^{+} \text {; Milner et al. } 1984 \dagger ; \\
\text { Simons et al. } 1966^{\dagger}\end{array}$ \\
\hline History of caretaker criminal behavior & w & $\begin{array}{c}\text { Altemeier et al. } 1982 \dagger ; \text { Baird } \\
1988^{*}\end{array}$ \\
\hline Parents' substance abuse $\ldots \ldots \ldots \ldots$ & $\underset{\mathrm{F}}{\mathrm{FRS}, \mathrm{W}, \mathrm{U}}$ & $\begin{array}{l}\text { Baird 1988*; Black and Mayer } \\
1980 \dagger ; \text { Famularo et al. } \\
1986 \dagger ; \text { Schneider et al. } \\
1976 \dagger\end{array}$ \\
\hline Age of caretaker ... & $\mathrm{W}, \mathrm{F}$ & $\begin{array}{l}\text { Baird 1988*; Bolton and } \\
\text { Belsky } 1986^{*} \text {; Hawkins and } \\
\text { Duncan 1985†; Levin et al. } \\
\text { 1985 } \dagger \text {; Miller 1984*; } \\
\text { Ragozin et al. } 1982 \dagger\end{array}$ \\
\hline History of victimization $\ldots \ldots$ & $\underset{\mathrm{W}}{\mathrm{ACT}, \mathrm{U}, \mathrm{F}}$ & $\begin{array}{l}\text { Altemeier et al. 1982 } \dagger \text {; Baird } \\
1988^{*} \text {; Conger et al. 1979†; } \\
\text { Hunter and Kilstrom 1979 ; } \\
\text { Newberger et al. } 1977 \dagger ;\end{array}$ \\
\hline Employment status of provider & W & 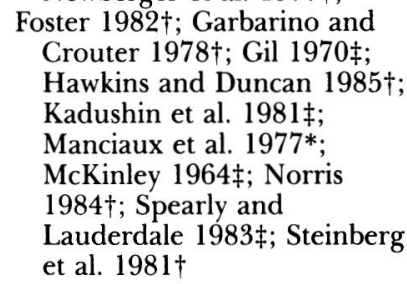 \\
\hline
\end{tabular}


Table A1 (Continued)

\begin{tabular}{ccc}
\hline $\begin{array}{c}\text { Variable } \\
(1)\end{array}$ & Instrument & Reference \\
$(2)$ & $(3)$ \\
\hline
\end{tabular}

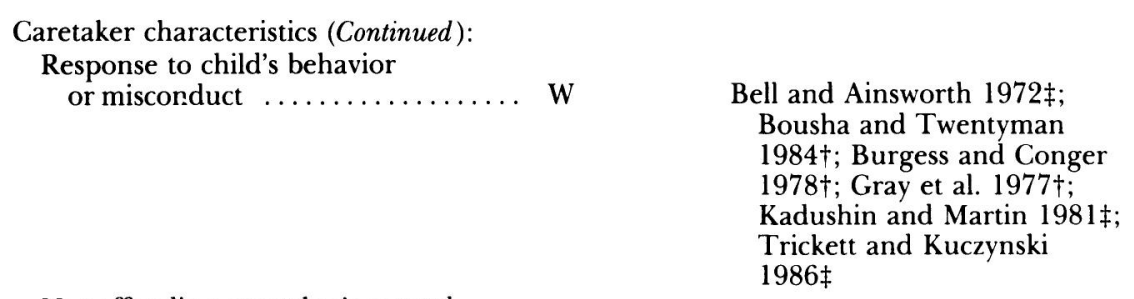

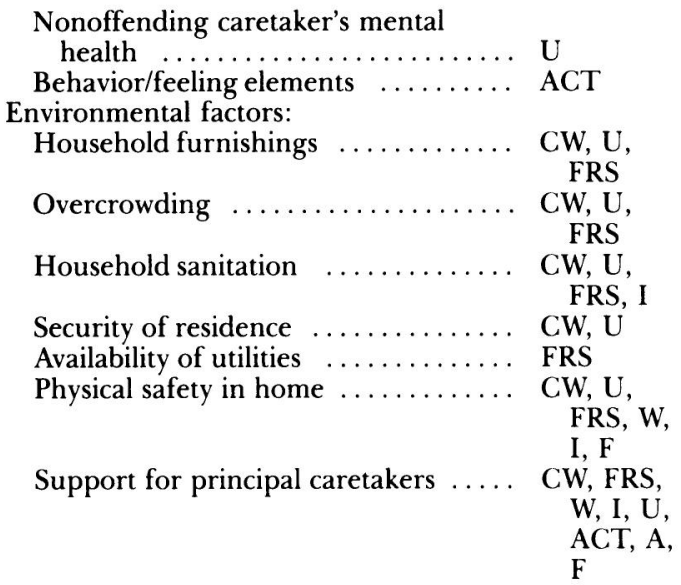

Stress on parents

W, I

Adequacy of education $\mathrm{CW}, \mathrm{U}$

Number of children in family ...... A

External barriers to intervention $\ldots$ A
Baird 1988*

Polansky et al. $1978 \dagger$

Polansky et al. $1978 \dagger$

Gil 1970*; Polansky et al. $1978 \dagger$

Altemeier et al. 1982†; Couron $1981 \dagger$; Crnic et al. $1983+$; Crockenberg 1981‡;

Garbarino 1976†; Garbarino and Crouter 1978+;

Garbarino and Sherman 1980*; Giovannoni and Billingsley 1970†; Hunter and Kilstrom 1979†; Johnson and l'Esperance 1984*; Milner et al. 1984†; Milner and Wimberley 1979†; Newberger et al. 1977†; Polansky et al. 1979†; Salzinger et al. $1983 \dagger$

Egeland and Brunnquelle 1979†; Elmer 1967 ;

Garbarino 1976†; Gil 1970‡;

Giovannoni and Billingsley 1970†; Helfer and Kempe 1972†; Johnson and l'Esperance 1984*; Justice et al. 1975 ; Kadushin and Martin 1981‡; Manciaux et al. 1977*; Milner et al. 1984†; Newberger et al. 1977†; Simons et al. 1966 ; Strauss 1979 ; WebsterStratton $1985 \dagger$

Baird 1988*; Johnson and l'Esperance 1984*; Simons et al. $1966 \ddagger$ 


\begin{tabular}{ccc}
\hline $\begin{array}{c}\text { Variable } \\
(1)\end{array}$ & Instrument & Reference \\
$(2)$ & $(3)$ \\
\hline
\end{tabular}

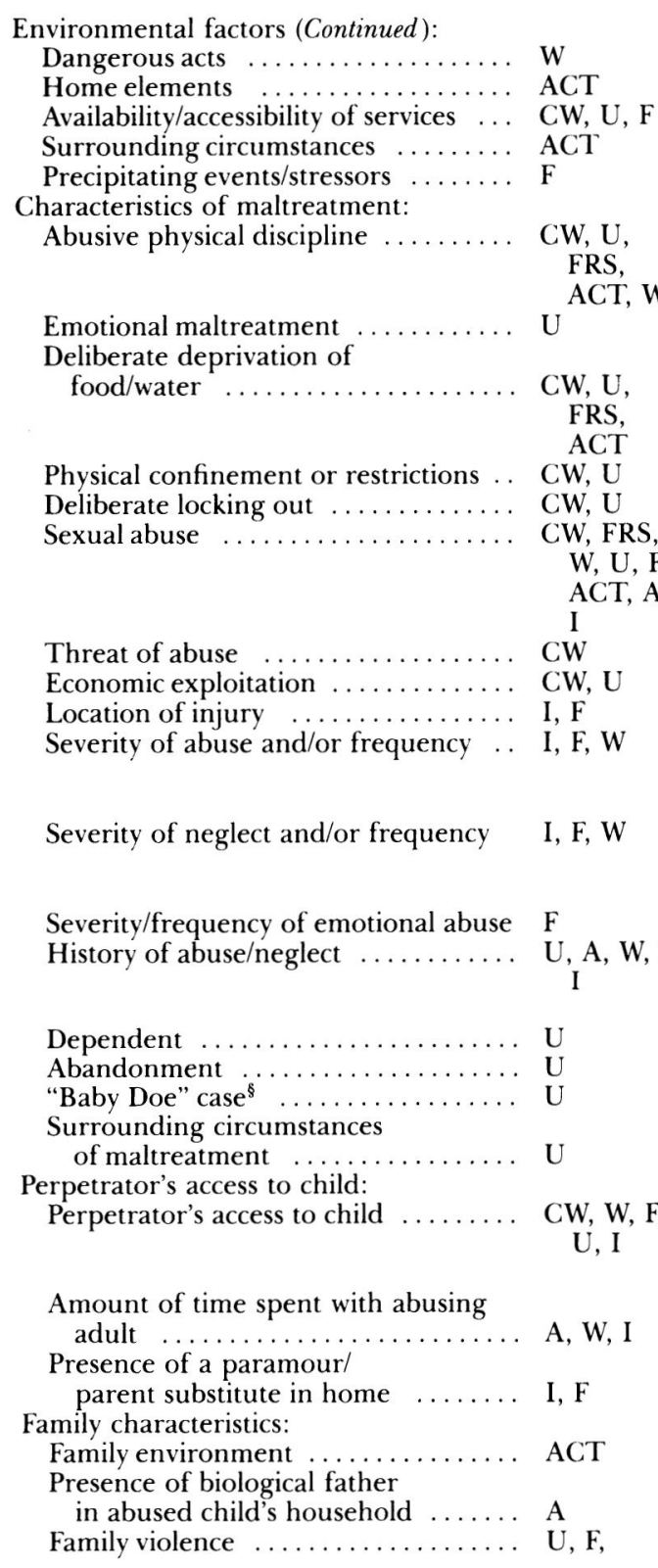

Garbarino $1976 \dagger$

George and Main 1979†

National Center on Child Abuse and Neglect 1982 ; Finkelhor 1986‡

Elmer 1967†; George and Main 1979†; Olmstead et al. 1981†; Simons et al. 1966‡

Olmstead et al. 1981†; Rosenberg et al. 1982†;

Simons et al. $1966 \ddagger$

Weedon et al. 1988*

Baird 1988*; Olmstead et al. 1981‡; Rosenberg et al. 1982†; Simons et al. 1966‡

\section{Baird 1988*}

Altemeier et al. 1982†; Conger et al. 1979†; Hunter and Kilstrom 1979†; Newberger et al. 1977†; O'Connor et al. 1979†; Simons et al. 1966‡; Steinmetz 1977 
Table A1 (Continued)

\begin{tabular}{|c|c|c|}
\hline $\begin{array}{l}\text { Variable } \\
\text { (1) }\end{array}$ & $\begin{array}{l}\text { Instrument } \\
\quad(2)\end{array}$ & $\begin{array}{l}\text { Reference } \\
\text { (3) }\end{array}$ \\
\hline \multicolumn{3}{|l|}{ Family characteristics (Continued): } \\
\hline Role reversal in family & $\mathrm{U}$ & Dean et al. $1986 \ddagger$ \\
\hline Victimization of other children $\ldots \ldots$ & W & Simons et al. $1966 \ddagger$ \\
\hline Attachment/bonding $\ldots \ldots \ldots \ldots \ldots$ & W & \\
\hline Person committing sexual abuse $\ldots .$. & $\mathrm{CW}$ & \\
\hline Degree of impairment $\ldots \ldots \ldots \ldots$ & $\mathrm{CW}$ & \\
\hline Impact of intervention & $\mathrm{F}$ & \\
\hline \multicolumn{3}{|l|}{ Parent-child interaction: } \\
\hline Child's family relations & CW, FRS, & $\begin{array}{c}\text { Egeland and Sroufe 1981†; } \\
\text { George and Main } 1979 \dagger\end{array}$ \\
\hline Continuity of parenting & $\mathrm{CW}, \mathrm{U}$ & \\
\hline Parental approval of child & CW, W, A & \\
\hline Parental expectations of child & $\begin{array}{l}\mathrm{CW}, \mathrm{U}, \mathrm{A} \\
\mathrm{W}, \mathrm{F}\end{array}$ & $\begin{array}{l}\text { Johnson and l'Esperance } \\
\text { 1984*; Milner et al. 1984†; } \\
\text { Milner and Wimberley } 1980 \dagger\end{array}$ \\
\hline Parental consistency of discipline $\ldots$. & $\begin{array}{l}\text { CW, U, } \\
\text { FRS, F }\end{array}$ & $\begin{array}{l}\text { Gelles 1980 } ; \text {; Polansky et al. } \\
\text { 1978†; Susman et al. } 1985 \ddagger\end{array}$ \\
\hline Parental teaching/stimulating child & $\mathrm{CW}, \mathrm{U}$ & \\
\hline Preparation for parenthood of child & FRS & \\
\hline Self-care of child $\ldots \ldots \ldots \ldots \ldots \ldots$ & W, I & \\
\hline
\end{tabular}

NOTE.-Column 2: instruments are abbreviated as follows: $\mathrm{A}=$ Alameda County California Reabuse Assessment Model; ACT = Action for Child Protection-Child at Risk Scales; $\mathrm{CW}=$ Child Welfare League of America Child Well-Being Scales; $\mathrm{F}=$ Florida Health and Rehabilitation Services Child Risk Assessment Matrix; FRS = Child Welfare League Family Risk Scales; I = Illinois CANTS 17B; U = Utah Risk Assessment Model; W = Washington Risk Factor Matrix.

* Prospective study: recidivism of reported or substantiated cases.

$\dagger$ Prospective or retrospective study: a study of abuse or neglect as an outcome (not recidivism) employing comparison groups.

$\ddagger$ Proxy measures for child abuse/neglect or incidence study describing characteristics of child abuse/neglect cases.

${ }^{\S}$ Parents refusing treatment for children born with congenital anomalies.

\section{Appendix B}

\section{References}

Altemeier, W.; O'Connor, S.; Vietze, P.; Sandler, H.; and Sherrod, K. "Antecedents of Child Abuse." Journal of Pediatrics 100, no. 5 (1982): 823-29.

Anderson R.; Ambrosino, K.; Valentine, D.; and Lauderdale, M. "Child Deaths Attributed to Abuse and Neglect: An Empirical Study." Children and Youth Services Review 1 (1983): 75-89.

Baird, C. "Development of Risk Assessment Indices for the Alaska Department of Health and Social Services." In Validation Research in CPS Risk Assessment: Three Recent Studies, edited by T. Tatara, Occasional Monograph Series, no. 2 (Washington, D.C.: American Public Welfare Association, 1988).

Bell, S. J., and Ainsworth, J. D. S. "Infant Crying and Maternal Responsiveness." Child Development 43, no. 4 (1972): 1171-90. 
Black, R., and Mayer, J. "Parents with Special Problems: Alcoholism and Opiate Addiction." In The Battered Child, $3 \mathrm{~d}$ ed., edited by C. H. Kempe and R. E. Helfer, pp. 104-14 (Chicago: University of Chicago Press, 1980).

Bolton, F., and Belsky, J. "The Adolescent Father and Child Maltreatment." In Adolescent Fatherhood, edited by A. Elster and M. Lamb, pp. 123-40 (Hillsdale, N.J.: Erlbaum, 1986).

Bousha, D., and Twentyman, D. "Mother-Child Interactional Style in Abuse, Neglect and Control Groups: Naturalistic Observations in the Home." Journal of Abnormal Psychology 93, no. 1 (1984): 10614.

Burgess, R., and Conger, R. "Family Interaction in Abusive, Neglectful and Normal Families." Child Development 49 (1978): 1163-73.

Conger, R.; Burgess, R.; and Barrett, C. "Child Abuse Related to Life Change and Perceptions of Illness: Some Preliminary Findings." Family Coordinator 28, no. 1 (January 1979): 73-78.

Couron, B. Assessing Parental Potentials for Child Abuse in Contrast to Nurturing (doctoral diss., United States International University, 1981).

Crnic, K.; Greenberg, M.; Ragozin, A.; Robinson, N.; and Basham, R. "Effects of Stress and Social Support on Mothers and Preterm and Full-Term Infants." Child Development 54 (1983): 209-17.

Crockenberg, S. "Infant Irritability, Mother Responsiveness, and Social Support Influences on the Security of Infant-Mother Attachment." Child Development 52 (1981): 857-65.

Dean, A.; Malik, M.; Richards, W.; and Stringer, S. "Effects of Parental Maltreatment on Children's Conception of Interpersonal Relationships." Developmental Psychology 22, no. 5 (1986): 617-26.

Dumas, J. E., and Wahler, R. G. "Predictors of Treatment Outcome in Parent Training: Mother Insularity and Socioeconomic Disadvantage." Behavioral Assessment 5 (1983): 301-13.

Egeland, B.; Breitenbucher, M.; and Rosenberg, D. "Prospective Study of Significance of Life Stress in the Etiology of Child Abuse." Journal of Consulting and Clinical Psychology 48, no. 2 (1980): 195-205.

Egeland, B., and Brunnquelle, B. A. "An At-Risk Approach to the Study of Child Abuse: Some Preliminary Findings." Journal of the American Academy of Psychiatry 18 (1979): 219-36.

Egeland, B., and Sroufe, L. "Attachment and Early Maltreatment." Child Development 52 (1981): 44-52.

Elmer, E. Children in Jeopardy: A Study of Abused Minors and Their Families (Pittsburgh: University of Pittsburgh Press, 1967).

Famularo, R.; Barum, R.; and Stone, K. "Court-ordered Removal in Severe Child Maltreatment: An Association to Parental Major Affective Disorder." Child Abuse and Neglect 10 (1986): 4878-92.

Finkelhor, D. A Sourcebook on Child Sexual Abuse (Beverly Hills, Calif.: Sage Publications, 1986).

Foster, D. "Referrals of Child Neglect to Child Protective Services: Status Characteristics Associated with Disposition" (doctoral diss., Case Western Reserve University, 1982). Dissertation Abstracts International 42, no. 7 (1982): 3304-A. 
Garbarino, J "Some Ecological Correlates of Child Abuse: The Impact of Socioeconomic Stress on Mothers." Child Development 47 (1976): $178-85$.

Garbarino, J., and Crouter, A. "Defining the Community Context of Parent-Child Relations: The Correlates of Child Maltreatment." Child Development 49 (1978): 604-16.

Garbarino, J., and Sherman, D. "High-Risk Neighborhoods and HighRisk Families: The Human Ecology of Child Maltreatment." Child Development 51 (1980): 188-98.

Gelles, R. "A Profile of Violence toward Children in the United States." In Child Abuse: An Agenda for Action, edited by G. Gerbner, C. J. Ross, and E. Zigler, pp. 82-105 (New York: Oxford University Press, 1980).

George, C., and Main, M. "Social Interactions of Young Abused Children: Approach, Avoidance, and Aggression." Child Development 50 (1979): 306-18.

Gil, D. Violence against Children: Physical Child Abuse in the United States (Cambridge, Mass.: Harvard University Press, 1970).

Giovannoni, J., and Billingsley, A. "Child Neglect among the Poor: A Study of Parental Adequacy in Families of Three Ethnic Groups." Child Welfare 4, no. 4 (1970): 196-204.

Gray, J., et al. "Prediction and Prevention of Child Abuse and Neglect." Child Abuse and Neglect 1 (1977): 45-58.

Hansburg, H. Adolescent Separation Anxiety (Springfield, Ill.: Charles C. Thomas, 1972).

Hawkins, W., and Duncan, D. "Perpetrator and Family Characteristics Related to Child Abuse and Neglect: Comparison of Substantiated and Unsubstantiated Reports." Psychological Reports 56, no. 2 (1985): 407-10.

Helfer, R., and Kempe, C. Helping the Battered Child and His Family (Philadelphia: Lippincott, 1972).

Hunter, R., and Kilstrom, N. "Breaking the Cycle in Abusive Families." American Journal of Psychiatry 136, no. 10 (1979): 1320-22.

Johnson, W., and l'Esperance, J. "Predicting the Recurrence of Child Abuse." Social Work Research and Abstracts 20, no. 2 (Summer 1984): $21-26$.

Justice, B.; Calvert, A.; and Justice, R. "Factors Mediating Child Abuse as a Response to Stress." Child Abuse and Neglect 9 (1975): 359-63.

Kadushin, A.; Martin, J.; and McGloin, J. Child Abuse: An Interactional Event (New York: Columbia University Press, 1981).

Levine, L.; Coll, C. T. G.; and Oh, W. "Determinants of Mother-Infant Interaction in Adolescent Mothers." Pediatrics 68 (1985): 684-90.

McKinley, D. Social Class and Family Life (New York: Free Press of Glencoe, 1964).

Manciaux, M.; Deschamps, G.; and Klein, O. "Prediction and Child Abuse." Child Abuse and Neglect 1 (1977): 59-61.

Miller, S. "The Relationship between Adolescent Childbearing and Child Maltreatment." Child Welfare 63, no. 6 (1984): 553-57.

Milner, J. S., and Ayoub, C. "Evaluation of 'At Risk' Parents Using 
the Child Abuse Potential Inventory." Journal of Clinical Psychology 36, no. 4 (1980): 945-48.

Milner, J. S.; Gold, R. G.; Ayoub, C.; and Jacewitz, M. M. "Predictive Validity of the Child Abuse Potential Inventory." Journal of Consulting and Clinical Psychology 52, no. 5 (1984): 879-84.

Milner, J. S., and Wimberley, R. C. "An Inventory for the Identification of Child Abusers." Journal of Clinical Psychology 35, no. 1 (1979): 95- 100 .

Milner, J. S., and Wimberley, R. C. "Prediction and Explanation of Child Abuse." Journal of Clinical Psychology 36, no. 4 (1980): 87584.

National Center on Child Abuse and Neglect. National Study of the Incidence and Severity of Child Abuse and Neglect, DHHS Publication no. ODHS 81-30329 (Washington, D.C.: Government Printing Office, 1982).

Newberger, E.; Reed, R.; Daniel, J.; Hyde, J.; and Kotelchuck, J. "Pediatric Social Illness: Toward an Etiologic Classification." Pediatrics 60 (1977): 178-85.

Norris, J. "The Distribution of Child Maltreatment Cases in Washington State" (Olympia, Wash.: Department of Social and Health Services, Office of Program Research and Evaluation, 1984).

O'Connor, S.; Altemeier, W.; Sherrod, K.; Sandler, H.; and Vietze, P. "Prospective Study of Non-organized Failure-to-thrive." Paper presented to Society for Research in Child Development, San Francisco, March 1979.

Olmstead, J.; Lichtenstein, K.; Hall, J.; Langenes, D.; and Thompson, J. Children's Service Needs Assessment Final Report 07-21 (Olympia, Wash.: Department of Social and Health Services, Office of Research, November 1981).

Polansky, N.; Chalmers, M.; Buttenweiser, E.; and Williams, D. "Assessing Child Care: An Urban Scale." Child Welfare 57, no. 7 (1978): 439-48.

Polansky, N.; Chalmers, M.; Buttenweiser, E.; and Williams, D. "The Isolation of the Neglectful Family." American Journal of Orthopsychiatry 49 (1979): 149-52.

Ragozin, A.; Basham, R.; Crnic, K.; Greenberg, M.; and Robinson, N. "Effects of Maternal Age on Parenting Role." Developmental Psychology 18, no. 4 (1982): 627-34.

Rosenberg, N. M.; Meyers, S.; and Shackelton, N. "Prediction of Child Abuse in an Ambulatory Setting." Pediatrics 70, no. 6 (1982): 87982.

Salzinger, S.; Kaplan, S.; and Artemyeff, C. "Mothers' Personal Social Networks and Child Maltreatment." Journal of Abnormal Psychology 92, no. 1 (1983): 68-76.

Schneider, C.; Helfer, R. B.; and Hoffmeister, J. K. "Screening for Potential Abuse: A Review." In The Battered Child, 3d ed., edited by C. H. Kempe and R. E. Helfer (Chicago: University of Chicago Press, 1980).

Schneider, C.; Hoffmeister, J. K.; and Helfer, R. B. “A Predictive 
Screening Questionnaire for Potential Problems in Mother-Child Interaction." In Child Abuse and Neglect: The Family and the Community, edited by R. Helfer and C. H. Kempe, pp. 343-407 (Cambridge, Mass.: Ballinger, 1976).

Simons, B.; Downs, E. F.; Hurster, M. M.; and Archer, M. "Child Abuse: Epidemiologic Study of Medically Reported Cases." New York State Journal of Medicine 66 (1966): 2783-88.

Spearly, J., and Lauderdale, M. "Community Characteristics and Ethnicity in the Prediction of Child Maltreatment Cases." Child Abuse and Neglect 7 (1983): 91-105.

Steinberg, L.; Catalano, R.; and Dooley, D. "Economic Antecedents of Child Abuse." Child Development 52 (1981): 975-85.

Steinmetz, S. "The Use of Force for Resolving Family Conflict: The Training Ground for Abuse." Family Coordinator 26 (1977): 19-26.

Strauss, M. "Family Patterns and Child Abuse in a Nationally Representative Sample." Child Abuse and Neglect 3 (1979): 213-25.

Susman, E.; Trickett, P.; Iannotti, R.; Hollenbeck, B.; and Zahn-Waxler, C. "Child Rearing Patterns in Depressed, Abusive, and Normal Mothers." American Journal of Orthopsychiatry 55, no. 2 (1985): $237-$ 51.

Trickett, P., and Kuczynski, L. "Children's Misbehaviors and Parental Discipline Strategies in Abusive and Nonabusive Families." Developmental Psychology 22, no. 1 (1986): 115-23.

Webster-Stratton, C. "Comparison of Abusive and Non-abusive Families with Conduct-disordered Children." American Journal of Orthopsychiatry 55, no. 1 (1985): 59-69.

Weedon, J.; Torti, T.; and Zunder, P. "Vermont Division of Social Services Family Risk Assessment Matrix Research and Evaluation." In Validation Research in CPS Risk Assessment: Three Recent Studies, edited by T. Tatara, pp. 3-43 (Washington, D.C.: American Public Welfare Association, 1988).

\section{Appendix C}

\section{Overview of Most Commonly Used Risk Factors}

Parent characteristics:

Mental health (7)

Physical health (7)

Capacity for child care (8)

Physical health care of child (7)

Supervision of children (5)

Cooperation with agency (7)

Environmental factors:

Support for caretaker (8)

Physical safety in home (6)

Parent-child interactions:

Expectations of child (5) 
Child characteristics:

Physical disabilities (5)

Personal hygiene (5)

Appropriate clothing (5)

Maltreatment:

Sexual abuse (7)

Abusive physical discipline (5)

Perpetrator:

Access to child (5)

Note.-The number in parentheses is the number of instruments that include the variable.

\section{Appendix D}

\section{Significant Predictors of Recurrence of Child} Maltreatment

Physical Abuse

Johnson and l'Esperance 1984:

Access to child

Parenting skill

Parental expectations

Capacity to use agency resources

More than one child in home

Baird 1988:

Prior reports of abuse

Prior placements

Problems listed-current referral

Number of adults in home

Number of children in home

Caretaker(s) abused

History of drug or alcohol abuse

Caretaker criminal history

Negative social relationships

Caretaker depression

Perpetrator or caretaker cooperation with agency

View of nonperpetrator caretaker

Neglect

Baird 1988:

Prior referrals

Prior placements

Problems noted in current referral

Caretaker(s) neglected 